\title{
Perancangan Aplikasi Chatbot Sebagai Media E-Learning Bagi Siswa
}

\author{
Muhammad Alifyan Zulkarnain ${ }^{1}$, Muhammad Fajri Raharjo ${ }^{2}$, Meylanie Olivya ${ }^{3}$ \\ ${ }^{1,2,3}$ Jurusan Teknik Elektro, Politeknik Negeri Ujung Pandang \\ *Corresponding Author, email: malifyanz@gmail.com
}

\begin{abstract}
Abstrak - Metode tanya-jawab secara konvensional memiliki keterbatasan waktu, ruang dan tingkat pemahaman dari masing-masing siswa sehingga menjadi kendala kurang efektifnya proses belajar-mengajar. Peristiwa pandemi global yang memberikan dampak negatif terhadap bidang pendidikan. Sehingga proses belajar mengajar dihentikan sementara disekolah dan dialihkan ke daring. Penelitian ini bertujuan untuk menghasilkan suatu aplikasi chatbot sebagai media pembelajaran jarak jauh yang membantu proses belajar-mengajar guru dan siswa. Pada penerapannya, penelitian ini menggunakan telegram sebagai media chatbot. Metode yang digunakan untuk pengumpulan data adalah dengan wawancara, studi literatur, dan observasi. Pengujian akan dilakukan dengan black box, perhitungan akurasi, serta user acceptance test berupa pembagian kuesioner. Hasil Penelitian ini menghasilkan Aplikasi Chatbot sebagai Media E-Learning Bagi Siswa yang dapat membantu guru dalam memberikan pembelajaran jarak jauh kepada siswa/i secara efisien dan mudah.
\end{abstract}

Kata kunci : E-learning, Chatbot, Telegram

Abstrack - The conventional question and answer method has limited time, space and level of understanding from each student so that it becomes an obstacle to the ineffective teaching and learning process. Global pandemic events that have a negative impact on the education sector. So that the teaching and learning process is temporarily stopped at school and diverted online. This study aims to produce a chatbot application as a media for distance learning that helps the teaching and learning process of teachers and students. In practice, This research uses telegram as a chatbot media. The method used for data collection is by interview, literature study, and observation. Testing will be carried out with a black box, calculation of accuracy, and a user acceptance test in the form of distributing questionnaires. The results of this study produce a Chatbot Application as an E-Learning Media for Students that can help teachers in providing distance learning to students efficiently and easily.

Keywords : E-learning, Chatbot, Telegram

(C) 2020 Elektron Jurnal Ilmiah

\section{I.PENDAHULUAN}

Perkembangan teknologi informasi dan komunikasi telah membawa pengaruh pada dunia pendidikan terutama dalam proses pembelajaran. Di era globalisasi sekarang ini, penggunaan TIK dalam proses pembelajaran bukan lagi hal yang asing [1]. Karena semua informasi yang diinginkan dapat diperoleh dengan menggunakan internet [2]. Salah satu inovasi teknologi yang telah berkembang adalah chatbot. Chatbot adalah program komputer yang dirancang untuk mensimulasikan percakapan atau komunikasi interaktif dengan pengguna (manusia) melalui teks, suara dan visual [3].

Chatbot dalam bidang pendidikan dapat dimanfaatkan untuk mengembangkan media pembelajaran bagi siswa sebagai penyaji materi dan kuis yang interaktif dan menarik [4]. Metode tanya jawab merupakan metode yang digunakan oleh guru dan siswa dalam proses pembelajaran. Dengan metode ini, memungkinkan terjadinya komunikasi yang sifatnya dua arah antara guru dan siswa [5], Namun permasalahan yang sering terjadi dengan metode tanya jawab konvensional adalah keterbatasan waktu, ruang dan tingkat pemahaman masing-masing siswa yang menjadi kendala dalam proses belajar mengajar sehingga kurang efektif [6].
Saat ini, terjadi sebuah pandemi global yang memberikan dampak terhadap gaya hidup manusia. Mulai 4 Maret 2020, UNESCO merekomendasikan penggunaan pembelajaran jarak jauh dan membuka platform pendidikan yang dapat digunakan sekolah dan guru untuk menjangkau pelajar dari jarak jauh dan membatasi gangguan pendidikan [7].

Berdasarkan wawancara dengan salah satu guru di SMP Negeri 16 Makassar, diperoleh informasi bahwa kondisi pembelajaran saat ini secara daring sangatlah berbeda dengan pembelajaran yang lalu, karena kurangnya interaksi langsung antara guru dan siswa sehingga pembelajaran menjadi kurang efektif dan keterbatasan tempat dan waktu serta kuota yang terbatas. Sehingga perlunya sebuah media pembelajaran jarak jauh berupa agen percakapan atau robot chatting yang dapat mendukung kinerja guru untuk menyampaikan ilmu pengetahuan sehingga dapat menjadi solusi untuk kelancaran proses belajar-mengajar, serta perlunya media pembelajaran yang dapat diakses oleh siswa dimana pun dan kapan pun.

Sampai saat ini penggunaan chatbot sudah diterapkan diberbagai bidang dan sangat membantu pekerjaan manusia seperti pada bidang pendidikan, 
sebuah penelitian membuat chatbot sebagai sarana pembelajaran bahasa inggris, dimana pelatihan bahasa inggris dilakukan dengan chatting sehingga seolah-olah user sedang berkomunikasi dengan tutor [8]. Pada bidang pariwisata chatbot memudahkan para wisatawan mendapatkan informasi alamat tempat wisata dengan melakukan interaksi tanya jawab dengan menggunakan bahasa sehari-hari layaknya model diskusi [9]. Pada bidang teknologi e-commerce media chatbot digunakan untuk memudahkan memberikan pelayanan lebih kepada pelanggan dalam waktu 24 jam [10]. Oleh karena itu hal ini sangat penting sebagai solusi interaktif guru dalam memberikan pelajaran jarak jauh kepada siswa secara efisien dan mudah untuk menyampaikan materi pembelajaran.

Berdasarkan uraian masalah di atas, maka akan dilakukan penelitian untuk merancang sebuah aplikasi e-learning dengan media chatbot yang diharapkan dapat membantu guru dan para siswanya belajar secara online dimanapun dan kapanpun.

\section{METODE PENELITIAN}

\section{A. Prosedur Penelitian}

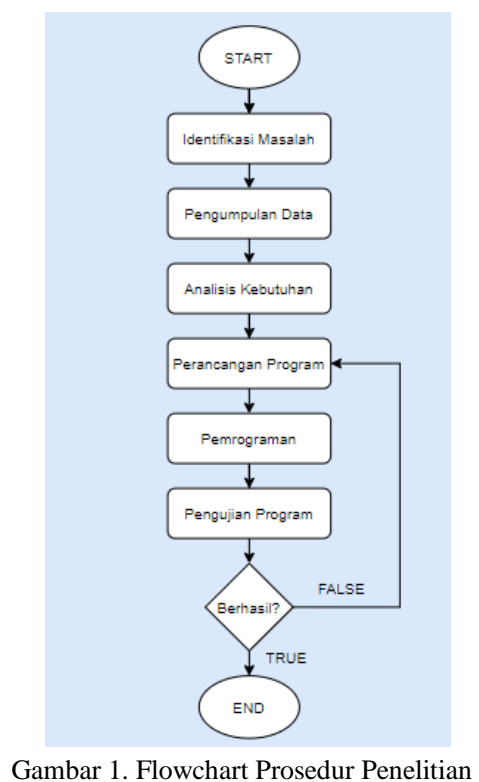

\section{B. Identifikasi Masalah}

Pada tahap ini dilakukan studi literatur dengan mempelajari, membaca, dan mencatat literatur dari beberapa buku maupun jurnal, serta melakukan observasi secara langsung di SMP Negeri 16 Makassar.

\section{Pengumpulan Data}

Pengumpulan data dilakukan agar dapat mengidentifikasi kalimat-kalimat percakapan yang mungkin terjadi ketika proses belajar-mengajar guru dan siswa. Data di ambil dari wawancara dengan guru serta dari buku bahasa Indonesia.
D. Analisis Kebutuhan Data

\section{Intents}

Data Intents bertujuan agar sistem mengenali atau memahami chat yang sampai kepadanya. Sedangkan Nama intents untuk memudahkan sistem menemukan jawaban dari pertanyaan dari user. Contoh data intents dapat dilihat pada tabel berikut.

Tabel 1. Contoh Data Intents

\begin{tabular}{clc}
\multicolumn{4}{c}{ Tabel 1. Contoh Data Intents } \\
\hline No & \multicolumn{1}{c}{ Data Intens } & Nama Intents \\
\hline 1. & $\begin{array}{l}\text { Apa pengertian dari } \\
\text { paragraf ? } \\
\text { 2. }\end{array}$ & $\begin{array}{l}\text { Sebutkan } \\
\text { paragraf ? }\end{array}$ \\
\hline
\end{tabular}

2. Entities

Data Entities bertujuan untuk memudahkan sistem memahami chat yang dimana pada intents tidak ditemukan sebuah kata tapi terdapat persamaan kata pada entities sehingga sistem mengenali chat yang sampai dengan bantuan kumpulan data pada entities.

Contoh data entities dapat dilihat pada tabel berikut.

Tabel 2. Contoh Data Entities

\begin{tabular}{|c|c|c|c|}
\hline No & Data Entities & Section & Keyword Entities \\
\hline 1. & $\begin{array}{l}\text { Definisi, Apa, Arti, } \\
\text { Maksud, Pengertian }\end{array}$ & Tanya & Definisi \\
\hline 2. & Apa, ap, apha, pa, apakah. & Tanya & Apa \\
\hline
\end{tabular}

Data Response yang diperlukan oleh sistem berupa materi pelajaran bahasa Indonesia yang bertujuan untuk menjadi balasan sistem kepada user ketika menanyakan materi pelajaran kepada sistem. Contoh Data response dapat dilihat pada tabel berikut.

Tabel 3. Contoh Data Response

\begin{tabular}{lll}
\hline No & \multicolumn{1}{c}{ Data Response } & Kata Kumci \\
\hline 1. $\quad \begin{array}{l}\text { Paragraf adalah suatu rangkaian } \\
\text { kalimat yang memiliki suatu } \\
\text { gagasan utama. }\end{array}$ & Paragraf \\
& $\begin{array}{l}\text { Teks ulasan adalah teks yang } \\
\text { berisi pembahasan atau penilaian } \\
\text { terhadap buku atau karya-karya } \\
\text { lain. }\end{array}$ & Teks Ulasan \\
&
\end{tabular}

E. Perancangan Program

1. Arsitektur Sistem

Arsitektur program merupakan penggambaran umum program yang akan dibuat 


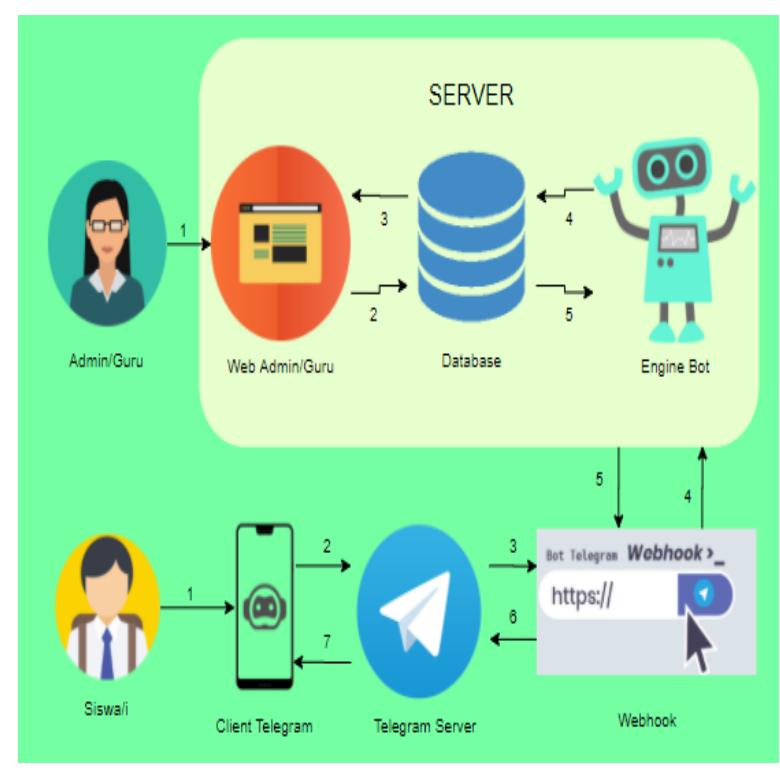

Gambar 2. Arsitektur Program

Gambar 2 akan dijelaskan berdasarkan dua sisi, yaitu dari Siswa/i dan Admin/Guru. Berikut penjelasannya :

A. Siswa/i

1. Sistem akan dibangun memanfaatkan fitur bot dari telegram yang digunakan untuk merespon pesan atau pertanyaan dari user.

2. Pesan akan diterima oleh telegram server.

3. Telegram dihubungkan dengan server menggunakan metode webhook dengan API Telegram. Pada server File engine bot dan website Admin/Guru telah di unggah dan memiliki sertifikat SSL.

4. Pesan diteruskan ke server dengan metode webhook yang telah terhubung untuk mendapatkan informasi atau data yang terdapat pada server.

5. Server akan mengirimkan tanggapan berupa pesan balasan kepada user sesuai dengan kondisi pertanyaan dengan menggunakan JSON.

6. Pesan balasan akan diteruskan kembali ke telegram server.

7. Kemudian Pesan diterima oleh user melalu client telegram.

B. Admin/Guru

1. Admin/Guru menginput materi pelajaran kedalam website.

2. Kemudian data materi pelajaran akan tersimpan kedalam database.

3. Data yang telah tersimpan didalam database dapat dilihat oleh Admin/Guru didalam halaman website untuk keperluan menghapus atau mengedit data materi pelajaran.

4. Engine Bot terhubung dengan database menggunakan API (application programming interface).

5. Engine Bot memperoleh data materi pelajaran dari database yang akan diteruskan sebagai pesan balasan berdasarkan pertanyaan dari user.

2. Use Case

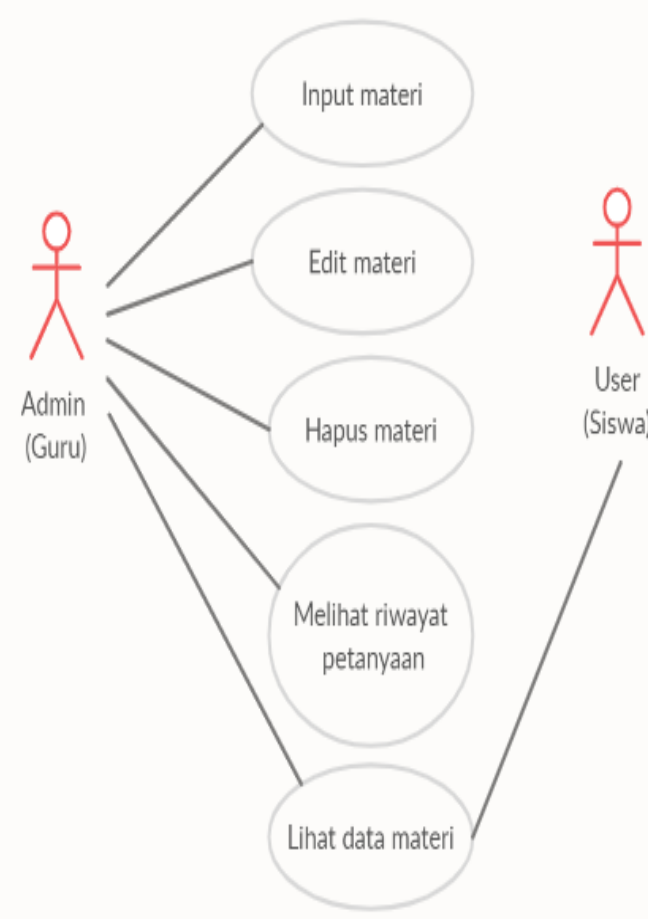

Gambar 3. Diagram Use Case

User dalam sistem ini dibagi menjadi dua aktor yang memiliki hak dan akses yang berbeda terhadap sistem yaitu Admin / Guru dan seluruh siswa/i kelas IX SMP Negeri 16 Makassar.

Admin / Guru dapat melihat, menambah (input data secara manual), dan menghapus data materi bahasa indonesia. Admin / Guru juga dapat melihat riwayat pertanyaan yang telah di ajukan oleh siswa/i melalui chatbot. Untuk hak user sebagai siswa/i SMP Negeri 16 Makassar dapat mengakses chatbot melalui telegram untuk melihat data materi bahasa indonesia.

\section{Flowchart Sistem}

Untuk memulai percakapan user akan menginput pesan lalu pesan akan diteruskan dan dimasukkan kedalam proses chatbot yaitu intents yang dimana pada proses ini pesan akan di cocokkan dengan beberapa pattern-pattern kalimat yang telah dialokasikan pada intents, Berikut Flowchart proses pada intents : 


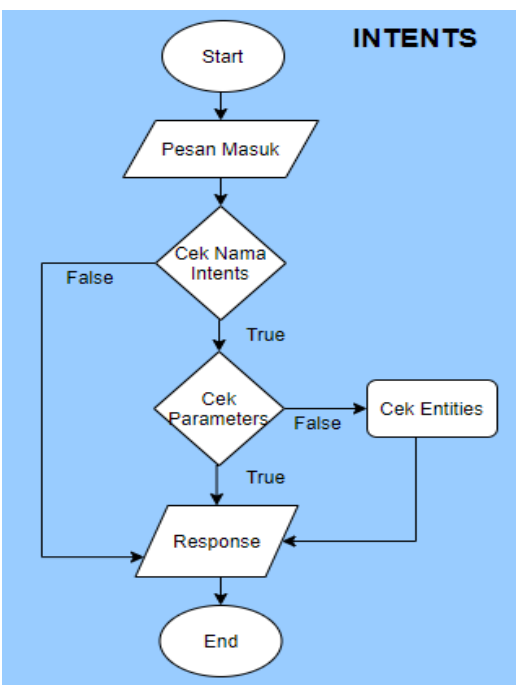

Gambar 4. Flowchart proses Intents

Pada beberapa kalimat dalam intents terdapat entities sesuai dengan kebutuhan pertanyaan. Berikut adalah Flowchart proses pada entities :

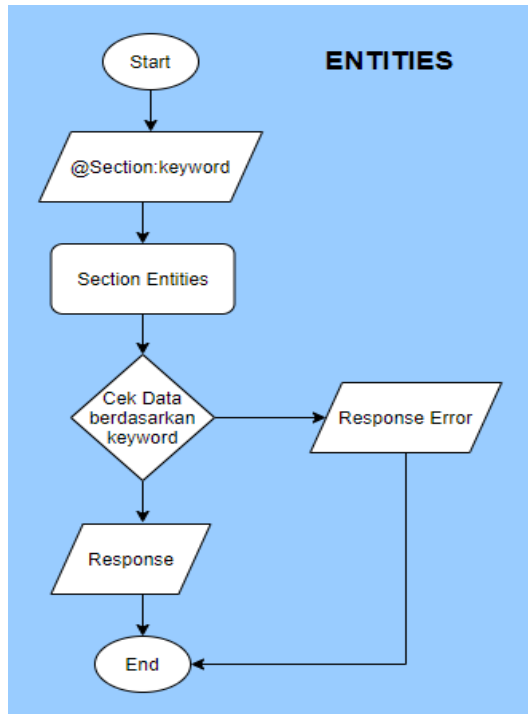

Gambar 5. Flowchart Proses Entities

Pada Proses entities, kata yang telah dirujuk pada entities akan dicocokkan dengan kata-kata yang telah disusun berdasarkan section dan keyword-nya jika terdapat persamaan kata maka akan memberikan berupa response benar namun jika tidak ditemukan makan akan memberikan response error.

Pada proses response, chatbot terdapat tiga jenis response. Pertama adalah response untuk bahasa alami, kedua adalah response untuk materi pelajaran bahasa indonesia, dan ketiga adalah response error untuk kalimat atau materi pelajaran yang tidak ditemukan pada sistem. Berikut Flowchart pada proses response :

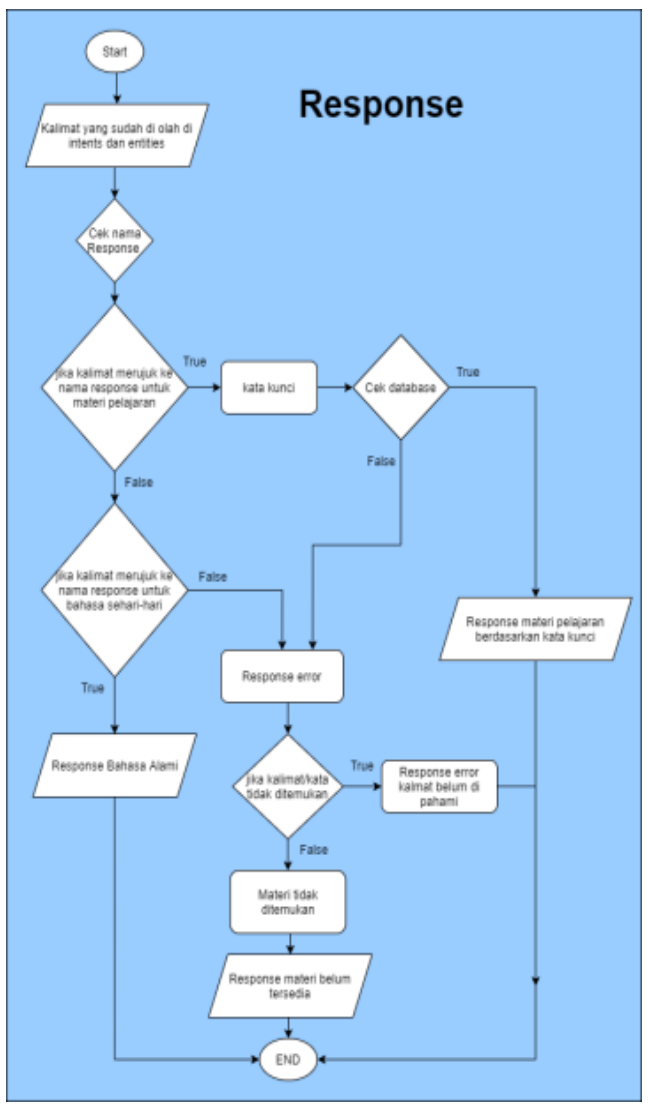

Gambar 6. Flowchart proses Response

\section{Metode Webhook}

Pada Penelitian ini metode webhook digunakan sebagai perantara bot dengan server (hosting). Metode webhook juga disebut web callback atau HTTP push API konsep untuk menangani request HTTP dengan sangat cepat karena berbasis aksi-reaksi. Metode ini membuat bot tidak harus melakukan update secara terus menerus ke server karena bot ditanam pada sebuah URL (Uniform Resource Locator), sehingga ketika pesan diterima, pesan tersebut akan diteruskan ke URL yang telah diatur untuk diproses lebih lanjut oleh bot. Telegram mengharuskan URL ini HTTPS.

\section{F. Pemrograman}

Program yang dibangun menggunakan Bahasa pemrograman PHP dan Database Mysql. Pada pemrograman ini, dibutuhkan sebuah perangkat lunak sebagai media untuk menuliskan kode bahasa pemrograman yaitu sublime text, dan juga sebuah interface web server dan database server yaitu XAMPP untuk membuat website dan menggunakan mysql-server.

\section{G. Pengujian Sistem}

Pengujian sistem dalam pembuatan Bot Telegram Pada Penelitian ini dilakukan dengan menggunakan empat cara yaitu : 
1. Pengujian Blackbox (blackbox testing)

2. Pengujian Akurasi

3. Pengujian User Acceptance Test

4. Pengujian Wireshark

\section{HASIL DAN PEMBAHASAN}

A. Implementasi Telegram Bot

\section{Proses Registrasi Bot Telegram}

Langkah awal dalam pembuatan Bot Telegram adalah melakukan proses registrasi bot baru yang akan dibantu dengan account BotFather. Setelah semua proses registrasi berhasil dilakukan, BotFather akan memberi informasi berupa API Token dari bot yang telah dibuat.

\section{Proses Webhook}

API Token kemudian digunakan untuk menghubungkan bot telegram dengan server menggunakan metode webhook agar dapat terhubung dengan engine bot yang telah di hosting pada server dan wajib menggunakan https. Ketika sudah melakukan webhook, otomatis chatbot pada telegram sudah dapat membalas pesan masuk dari user dengan memanfaatkan NLP dari engine carik untuk memberikan respon bahasa alami. Contoh balasan chatbot dalam bahasa alami dapat dilihat pada gambar 7 .

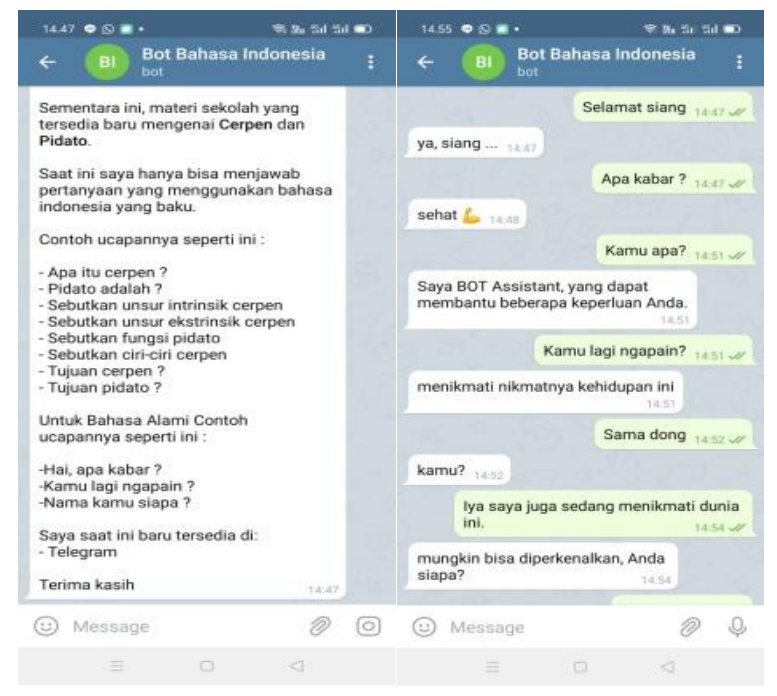

Gambar 7. Contoh balasan Chatbot Bahasa alami

\section{Proses Pembuatan Response Mata Pelajaran}

Pada engine carik ditambahkan sebuah fitur agar user mendapatkan balasan dari chatbot berupa mata pelajaran. Pada intents dan entities ditambahkan kalimat yang kemungkinan akan ditanyakan oleh siswa. Untuk memudahkan chatbot mengenali banyak kata yang kemungkinan akan muncul pada saat user bertanya maka dibuatkan entities pada tiap pertanyaan yaitu @section:keyword yang akan merujuk pada entities 'section'. Lalu kemudian pada tiap pertanyaan diberikan kode @katakunci sebagai pengenal mata pelajaran yang terhubung dengan Database.

\section{Proses Menghubungkan Database}

Pada tahap ini, dalam response diberikan kode link yang merujuk ke API untuk mendapatkan balasan dari Database. Kode yang digunakan adalah sebagai berikut :

[Definisi]

say=json:https://alifyan.hasbullahmarwan.com/script s/echo/?type=definisi

Agar chatbot dapat mengenali nama intent yang telah dimasukkan kedalam intents dan menjawab sesuai dengan nama intent maka dibuatkan sebuah kode untuk tiap-tiap nama intent.

Setelah menghubungkan chatbot dengan Database maka user dapat menanyakan kepada chatbot perihal mata pelajaran yang ingin ditanyakan. Berikut adalah contoh percakapan dengan response mata pelajaran yang dapat dilihat pada gambar 8 :

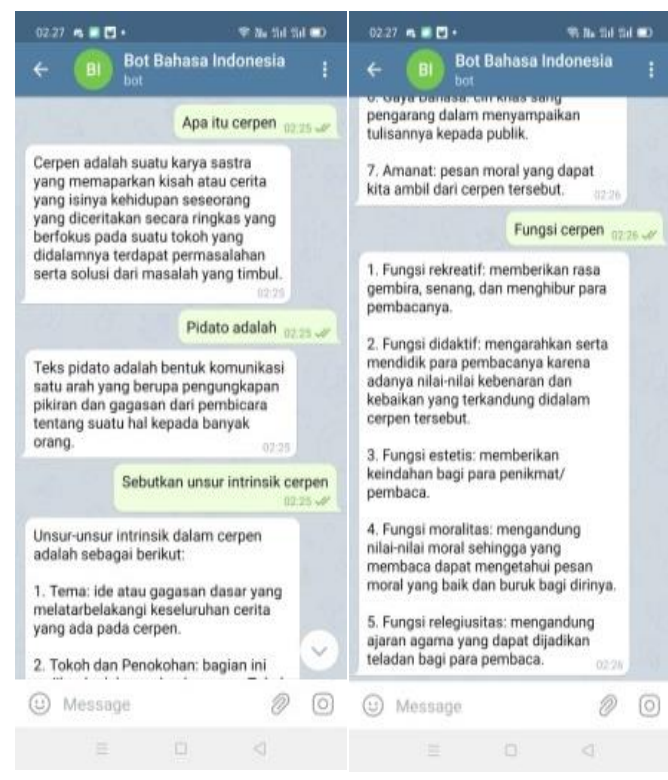

Gambar 8. Contoh Percakapan dengan balasan Materi Pelajaran

\section{Proses Membuat Respon Error}

Pada tahap ini, dibuatkan dua pesan error yang bertujuan untuk membalas pertanyaan user. Yang pertama adalah pesan error jika user menggunakan pertanyaan yang tidak ada pada intents maupun entities dan yang kedua adalah pesan error jika user menanyakan materi yang tidak tersedia di website menggunakan intents 
mata pelajaran. Gambar berikut adalah contoh percakapan pesan error pada chatbot:

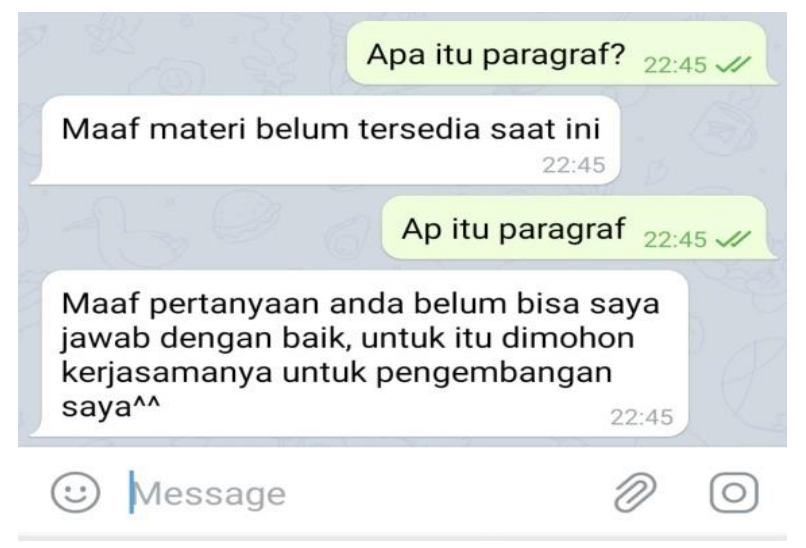

Gambar 9. Percakapan pesan Error

\section{B. Implementasi Website}

Aplikasi web ini digunakan sebagai wadah bagi guru untuk menginput materi pelajaran. Berikut adalah tampilan interface dari aplikasi web:

\section{Halaman Materi Pelajaran}

Halaman Materi Pelajaran merupakan halaman untuk melihat, menambah, mengubah, dan menghapus Materi Pelajaran.

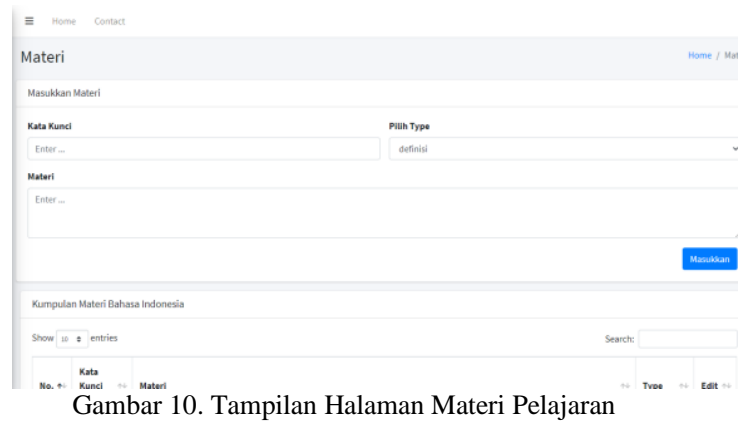

\section{Halaman Riwayat}

Halaman riwayat merupakan halaman untuk melihat dan menghapus kalimat-kalimat dari pertanyaan user yang direspon pesan error oleh chatbot dan tersimpan kedalam Database.

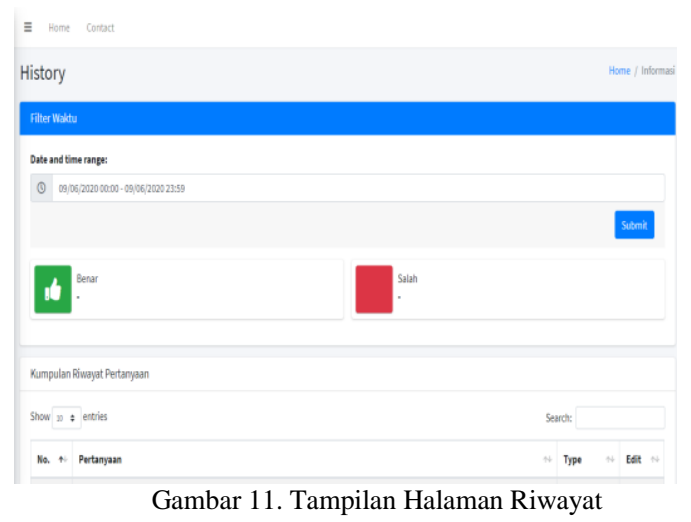

\section{Pengujian Sistem}

\section{Pengujian Blackbox}

Pengujian blackbox pada aplikasi Bot Telegram dalam penelitian ini meliputi pengujian chatbot dan pengujian terhadap halaman website. Pengujian dengan menggunakan blackbox testing ini bertujuan agar seluruh sistem yang dibuat dapat berfungsi sesuai dengan yang diharapkan.

\section{Pengujian Akurasi}

Pengujian Akurasi chatbot dilakukan untuk mengetahui seberapa akurat respon jawaban yang diberikan chatbot atas pertanyaan user. Pengujian dilakukan di SMP Negeri 16 Makassar pada tanggal 12 September 2020 secara daring dengan subjek sebanyak 80 orang. Rumus yang digunakan untuk mengukur seberapa tepat chatbot dalam menjawab pertanyaan user adalah sebagai berikut :

Akurasi $=\frac{\text { Jumlah jawaban sesuai }}{\text { Jumlah pertanyaan }} \times 100 \%$

Pada Gambar 12. adalah hasil dari pengujian akurasi yang telah difilter berdasarkan waktu pengujian yaitu pada tanggal 12 September dan pada waktu 01:00 PM sampai dengan 04:00 PM.

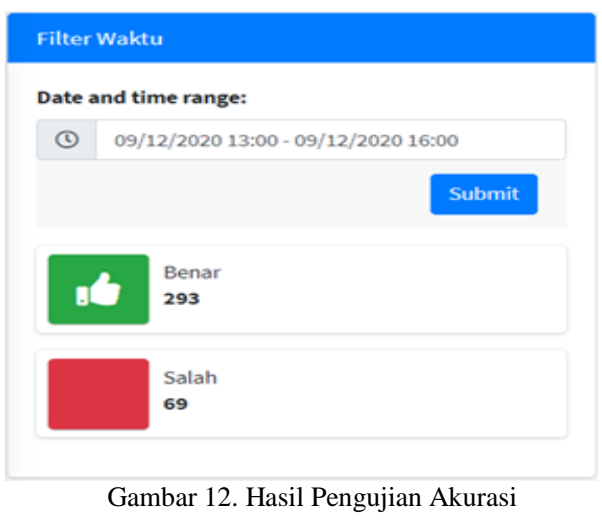

Berdasarkan gambar 4.10, maka didapatkan hasil benar sebanyak 293 dan salah sebanyak 69 sehingga mendapatkan presentase sebagai berikut.

$$
\text { Akurasi }=\frac{293}{362} \times 100 \%=81 \%
$$

Maka dapat disimpulkan bahwa presentase chatbot dalam menjawab pertanyaan secara akurat memiliki ketepatan $81 \%$ dari $100 \%$.

\section{Pengujian User Acceptance Test}

Pengujian yang dilakukan dengan memberikan kuesioner kepada siswa untuk mencoba sistem tersebut dan mengetahui 
apakah sistem telah memenuhi tujuannya dengan baik. Pada pengujian ini kuesioner diberikan kepada 80 responden siswa SMP Negeri 16 Makassar. Data tentang jawaban responden dapat dilhat pada tabel 4 berikut.

Tabel 4. Jawaban Responden

\begin{tabular}{|c|c|c|c|c|c|c|}
\hline \multirow{2}{*}{ No } & \multirow{2}{*}{ Pertannyaan } & \multicolumn{5}{|c|}{ Penilaian } \\
\hline & & TS & $\mathrm{KS}$ & $\mathrm{CS}$ & $\mathrm{S}$ & SS \\
\hline 1 & $\begin{array}{l}\text { Saat berinteraksi } \\
\text { dengan chatbot, } \\
\text { apakah } \\
\text { berpikir bahda } \\
\text { yang menjawab } \\
\text { pertanyaan anda } \\
\text { adalah manusia } \\
\text { juga. }\end{array}$ & 9 & 4 & 9 & 29 & 29 \\
\hline 2 & $\begin{array}{l}\text { Berinteraksi } \\
\text { dengan chatbot } \\
\text { lebih menarik } \\
\text { dibandingkan } \\
\text { dengan aplikasi } \\
\text { web biasa. }\end{array}$ & 1 & 2 & 17 & 30 & 30 \\
\hline 3 & $\begin{array}{l}\text { Saya tertarik untuk } \\
\text { sering } \\
\text { menggunakan } \\
\text { chatbot ini. }\end{array}$ & 0 & 1 & 9 & 49 & 21 \\
\hline 4 & $\begin{array}{l}\text { Chatbot ini mudah } \\
\text { untuk digunakan. }\end{array}$ & 0 & 2 & 8 & 45 & 25 \\
\hline 5 & $\begin{array}{l}\text { Menurut saya, } \\
\text { chatbot ini akan } \\
\text { mudah digunakan } \\
\text { oleh banyak orang. }\end{array}$ & 0 & 0 & 7 & 42 & 31 \\
\hline 6 & $\begin{array}{l}\text { Saya merasa } \\
\text { nyaman } \\
\text { menggunakan } \\
\text { chatbot ini. }\end{array}$ & 0 & 0 & 9 & 35 & 36 \\
\hline 7 & $\begin{array}{l}\text { Saya cukup puas } \\
\text { terhadap } \\
\text { kecepatan chatbot } \\
\text { dalam menjawab } \\
\text { pertanyaan. }\end{array}$ & 0 & 2 & 5 & 29 & 44 \\
\hline 8 & $\begin{array}{lr}\text { Aturan } & \text { penyajian } \\
\text { materi } & \text { dalam } \\
\text { aplikasi } & \text { chatbot } \\
\text { tidak } & \text { membuat } \\
\text { saya kebingungan. }\end{array}$ & 1 & 2 & 7 & 34 & 36 \\
\hline 9 & $\begin{array}{l}\text { Saya akan selalu } \\
\text { menggunakan } \\
\text { aplikasi chatbot } \\
\text { ini dalam proses } \\
\text { belajar. }\end{array}$ & 0 & 3 & 8 & 31 & 38 \\
\hline
\end{tabular}

Skala jawaban: TS, Tidak Setuju; KS, Kurang Setuju; CS, Cukup Setuju, S, Setuju; SS, Sangat Setuju. Berdasarkan hasil kuesioner yang diberikan kepada pengguna, dapat dicari prosentase masing-masing jawaban dengan menggunakan rumus :

$$
P=\frac{S}{\text { Skor Ideal }} \times 100 \%
$$

Dengan Keterangan :

$\mathrm{P}=$ Nilai presentasi yang dicari

$\mathrm{S}=$ Jumlah frekuensi dikalikan dengan skor yang dimiliki tiap jawaban

Skor Ideal $=$ Skor tertinggi dikalikan dengan jumlah sampel

Berikut ini adalah bobot dari masingmasing jawaban kuisoner : Jawaban TS diberi nilai 1, Jawaban KS diberi nilai 2, Jawaban CS diberi nilai 3, Jawaban S diberi nilai 4, Jawaban SS diberi nilai 5, dan kemudian diinterpretasikan dalam skor hasil perhitungan pada tabel 5.

\begin{tabular}{cccc}
\multicolumn{4}{c}{ Tabel 5. Kategori penilaian } \\
\hline $\begin{array}{c}\text { Skala } \\
\text { Jawaban }\end{array}$ & Keterangan & Skor & Presentase \\
\hline SS & Sangat Setuju & 5 & $100 \%-80 \%$ \\
S & Setuju & 4 & $79 \%-60 \%$ \\
CS & Cukup Setuju & 3 & $59 \%-40 \%$ \\
KS & Kurang Setuju & 2 & $39 \%-20 \%$ \\
TS & Tidak Setuju & 1 & $19 \%-0 \%$
\end{tabular}

Adapun hasil yang diperoleh dari memberikan kuisoner kepada 25 pengguna diperoleh hasil akhir setiap pertanyan seperti pada tabel 6.

Tabel 6. Hasil Akhir Setiap pertanyaan

\begin{tabular}{ccc}
\hline $\begin{array}{c}\text { No } \\
\text { Pertanyaan }\end{array}$ & Skor & Kesimpulan \\
\hline 1 & $76 \%$ & Setuju \\
2 & $81.5 \%$ & Sangat Setuju \\
3 & $82.5 \%$ & Sangat Setuju \\
4 & $83 \%$ & Sangat Setuju \\
5 & $86 \%$ & Sangat Setuju \\
6 & $86.75 \%$ & Sangat Setuju \\
7 & $88.75 \%$ & Sangat Setuju \\
8 & $85.5 \%$ & Sangat Setuju \\
9 & $86 \%$ & Sangat Setuju \\
\hline
\end{tabular}

Hasil rata-rata yang diperoleh dari hasil akhir setiap pertanyaan menunjukkan bahwa sistem telah dapat diterima pengguna dengan nilai sebesar $84 \%$ yang artinya pengguna setuju dengan fitur dan pengembangan aplikasi tersebut.

\section{Pengujian Wireshark}

Telegram mengharuskan URL dalam bentuk HTTPS sehingga pada pengujian wireshark ini dilakukan untuk memantau paket data pada website dan chatbot. Sehingga diketahui apakah website sudah ter-certificate SSL atau tidak. 


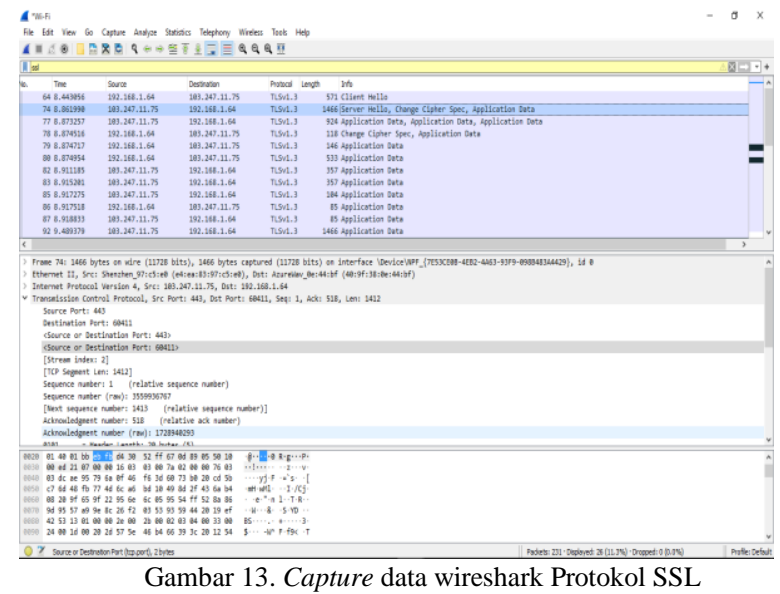

Pada Gambar 13 menunjukan bahwa saat mengakses website https://alifyan.hasbullahmarwan.com, kemudian menjalankan wireshrak dan memfilter protokol SSL, terlihat client (103.247.11.75) mengirimkan pesan Client Hello untuk mengajukan opsi SSL ke server atau database (192.168.1.64). Untuk melihat apakah data sudah terenkripsi ditunjukkan pada Gambar 14.

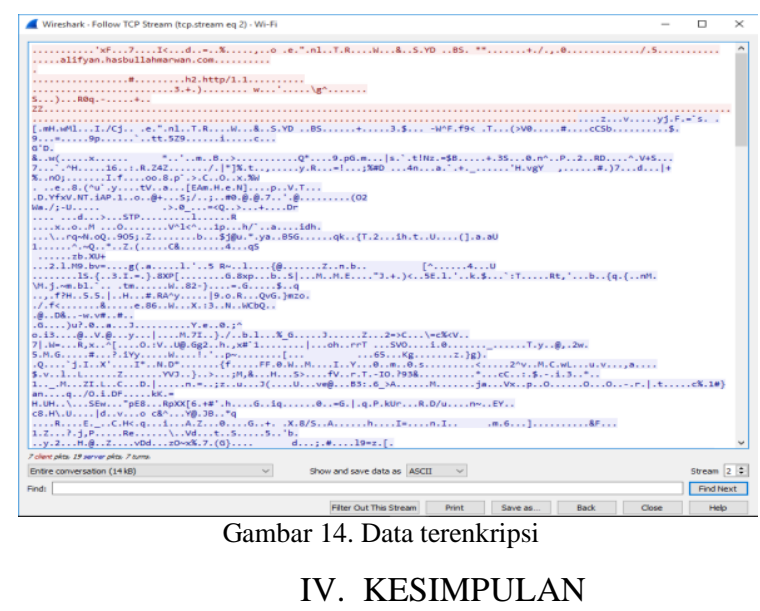

Chatbot E-learning berhasil dibuat dengan menggunakan engine bot Carik dan terhubung ke Database sehingga dapat merespon pertanyaan dari user berdasarkan pengujian Black Box. Berdasarkan pengujian User Acceptance Test dapat diambil kesimpulan bahwa chatbot ini dapat diterima dengan baik oleh Guru dan Siswa SMP Negeri 16 Makassar dan berdasarkan pengujian akurasi chatbot, untuk menjawab pertanyaan secara akurat chatbot memiliki ketepatan $81 \%$ dari $100 \%$. Adapun saran yang penulis berikan untuk pengembangan kedepannya adalah:

1. Menambahkan fitur-fitur baru seperti fitur untuk kumpul tugas dan semacamnya.

2. Menambahkan games / quiz pertanyaan agar lebih menarik.
3. Menambahkan materi pelajaran yang baru seperti fisika, kimia, dan sebagainya.

\section{REFERENSI}

S. Lestari, "PERAN TEKNOLOGI DALAM PENDIDIKAN DI ERA GLOBALISASI," vol. 2, 2018.

[2] Amin Akbar and N. Noviani, "TANTANGAN DAN SOLUSI DALAM PERKEMBANGAN TEKNOLOGI PENDIDIKAN DI INDONESIA,” 2019.

[3] D. S. Hormansyah and Yoga Putera Utama, "Aplikasi Chatbot Berbasis Web Pada Sistem Informasi Layanan Publik Kesehatan di Malang dengan menggunakan Metode TF-IDF," Inform. Polinema, vol. 4, p. 1, 2018.

[4] H. T. Mokhamad Hadi Wijaya, Moechammad Sarosa, "RANCANG BANGUN CHATBOT PEMBELAJARAN JAVA PADA GOOGLE CLASSROOM DAN FACEBOOK MESSENGER," Teknol. Inf. dan Ilmu Komput., vol. 5, 2018.

[5] Fathony, "PENGARUH METODE TANYA JAWAB TERHADAP HASIL BELAJAR SISWA DI SMK NEGERI 1 PERANAP KABUPATEN INDRAGIRI HULU," vol. 3, pp. 88-89, 2019.

[6] M. A. Hakim, "Pembangunan Aplikasi Chatbot Midwify sebagai media pendukung pembelajaran Ilmu Kebidanan berbasis Android di Stikes Bhakti Kencana Bandung," p. 2, 2019.

[7] A. R. Setiawan, "Lembar Kegiatan Siswa untuk Pembelajaran Jarak Jauh Berdasarkan Literasi Saintifik pada Topik Penyakit Coronavirus 2019 (COVID-19)," Arij Zulfi Mufassaroh, 2020.

[8] M. Sarosa, M. Kusumawardani, A. Suyono, and Zamah Sari, "CHATBOT PEMBELAJARAN BAHASA INGGRIS BERBASIS MEDIA SOSIAL,” 2018.

[9] D. Suryani and E. L. Amalia, "Aplikasi Chatbot Objek Wisata Jawa Timur Berbasis AIML," vol. 3, no. 2, pp. 47-54, 2017.

[10] Shafira Anggraini, "Implementasi Chatbot Sebagai Strategi Untuk Memperoleh Pelanggan (ACQUIRE) Pada Prosehat (PT. Atoma Medical),”p. 3, 2018. 